\title{
Recent advances in the analysis of biological particles by capillary electrophoresis
}

\author{
Vratislav Kostal and Edgar A. Arriaga \\ Department of Chemistry, University of Minnesota, Minneapolis, MN, USA
}

\begin{abstract}
This review covers research papers published in the years 2005-2007 that describe the application of capillary electrophoresis to the analysis of biological particles such as whole cells, subcellular organelles, viruses and microorganisms.
\end{abstract}

\author{
Keywords \\ Cells; Fluorescence; Microorganisms; Mitochondria; Viruses
}

\section{Introduction}

The CE presents many advantages: it can be used to perform fast analyses with high efficiencies that require only small sample volumes. It also can be easily automated [1]. These features made CE attractive for the development of methods for separating DNA fragments, proteins, peptides, small organic molecules, and inorganic ions; these methods have been comprehensively summarized in recent reviews [2-5]. More recently, CE has been proven to be suitable for characterizing larger assemblies (i.e. in the nm- to $\mu \mathrm{m}$-range), including various types of inorganic and polymeric particles, colloidal suspensions, cells, organelles, microorganisms and viruses [6]. In this review, we describe the research papers published in the last three years that deal with the subsets of large assemblies that are biological in origin, to be referred hereafter as "bioparticles" (see Table 1).

\section{Bioparticle electrophoresis - fundamentals}

There has been some progress in developing theories that describe the electrophoretic mobility of bioparticles using liposomes as models [7-9]. Other work focusing on the use of liposomes as stationary phases, or earlier work on the analysis of liposomes by CE, has already been covered in two recent reviews $[10,11]$ and is outside our scope. Up to now, classical electrokinetic theories about colloidal particles have been only partially successful in describing the electrophoretic mobility of liposomes as a complex function of their size, geometry, $\zeta$ potential, and the ionic strength of the medium. While these theories help us better understand the origins of the electrophoretic mobility of bioparticles, they do not take into account the contributions of the rigidity, surface charge distribution, field-induced polarization, and capacitive effects to the observed electrophoretic behavior of liposomes and other bioparticles.

Correspondence: Professor Edgar A. Arriaga, Department of Chemistry, University of Minnesota, 207 Pleasant St. SE, Minneapolis, MN 554 55, USA, arriaga@umn.edu, Fax: 11-612-626-7541.

The authors have declared no conflict of interest. 
The Hayes group has made important advances in defining the electrophoretic behavior of liposomes. They used CE to analyze liposomes with different cholesterol contents, which affected the liposome's rigidity. They were able to confirm that the electrophoretic behavior of rigid liposomes, (i.e. those with higher cholesterol content), is more similar to that predicted for rigid particles, while the behavior of the 'softer' deformable liposomes is better described by the electrokinetic theories for elongated or spheroidal particles [8].

Subsequently, they demonstrated that different surface charge distributions and polarizabilities help predict the electrophoretic behavior of liposomes [9]. The effects of the $\mathrm{pH}$ gradients across the membrane of liposomes and acidic organelles on their electrophoretic mobilities were also investigated [7]. When the internal $\mathrm{pH}$ is higher than the external $\mathrm{pH}$, the liposomes have more negative electrophoretic mobilities, which is consistent with a capacitive model. However, when the internal $\mathrm{pH}$ is lower than the external $\mathrm{pH}$, such as in the case of acidic organelles, other theories may be required (e.g. flip-flop of lipids) to explain the electrophoretic behaviors observed [7].

The issue of bioparticle stability in the presence of electric fields is also particularly relevant to advancements in the CE analysis of bioparticles. Recently, Hayes [12] has provided clear examples of how the deformation of certain liposomes in the presence of an electric field can result in stretched structures such as nanotubes and long-ranged organized assemblies. Although it is not known whether this behavior is characteristic of other bioparticles, these findings imply that some bioparticles may not be compatible with CE-based analyses.

Direct observations of changes in the electrophoretic behavior of bioparticles due to modifications to their surfaces are also of importance for electrokinetic theories. Two elegant examples, which are also relevant for understanding the electrophoretic behavior of viruses, refer to the use of liposomes incorporating $\mathrm{Ni}$-nitrilotriacetate carrying lipids into the liposomal membranes $[13,14]$. In each case, upon binding of the His 6 -tagged proteins, there was a clear shift in the electrophoretic mobility of the liposomes, confirming that basic electrophoretic principles are useful when designing and predicting the results of bioparticles CE analysis.

\section{Cells and microorganisms}

\subsection{Intact cells}

Most of the CE reports dealing with cells refer to either the separation and analysis of single-cell contents or the separation of cell types based on electrophoretic behavior. The first category is outside the scope of this review and the interested reader is referred to the literature [15-17]. The cell types that have been analyzed to date are unicellular organisms (e.g. Escherichia coli), fungi (e.g. Saccharomyces cerevisiae), and cultured cells (e.g. 143B cells).

A CE-LIF method for characterizing a P-glycoprotein (PGP) in a single cell was reported by Xiao et al. [18]. The PGP in question is a membrane-bound glycoprotein responsible for transporting a variety of amphophilic substances. Its production is controlled by the MDR-1 gene, whose over-expression is related to the multidrug resistance of some anticancer drugs. The PGP labeling was done in permeabilized K562 cells by combining primary antibody JSB-1 and secondary fluorescent antibody IgG-FITC (GAMIF). After labeling, the intact cells were separated by CE, and the fluorescence corresponding to the labeled PGP was detected using LIF detection.

Several groups have used microfluidic devices in the analysis of intact cells and their properties. Omasu et al. [19] measured the electrophoretic mobilities of sheep erythrocytes and the effects of nonspecific adhesion to micro-channels coated with different coatings. 
Akagi et al. [20] used a microfluidic chip to determine the cell-cycle stages of HL-60 cells by measuring the differences between their electrophoretic mobilities. An on-chip method for the simultaneous monitoring of enzyme activity in a single cell, with and without cytolysis, was developed by Gao et al. [21]. Here, peroxidase (PO) in neurophils was chosen as a model system. In this method, the plasma membrane was first perforated with digitionin. After that, the permeabilized cell was delivered into the double-T injector on the chip, which contained the enzyme substrate hydroquinone $\left(\mathrm{H}_{2} \mathrm{Q}\right)$ and hydrogen peroxide $\left(\mathrm{H}_{2} \mathrm{O}_{2}\right)$ in a physiological buffer saline. Small molecules like $\mathrm{H}_{2} \mathrm{Q}$ and $\mathrm{H}_{2} \mathrm{O}_{2}$ diffused into the cell, where they were converted by PO into benzoquinone (BQ). BQ diffused back from the cell into the chip and formed a zone around the cell, while PO remained in the cell. The $\mathrm{BQ}$ zone and the cell were electrophoretically separated by briefly applying high voltage. Then, the cell was lysed by the short pulse of a high electric potential and the PO released reacted with the substrates, forming a second zone of BQ. Finally, both BQ zones were electrophoretically separated and detected electrochemically. The concentration ratio of $\mathrm{BQ}$ corresponding to PO activity with and without cytolysis was calculated from the electropherogram.

\subsection{Microorganisms}

Most reported separations were based on dynamically modified capillaries (e.g. polyethylene oxide [22-25] or PEG [26]) with only one report of using capillaries with covalent modifications using trimethylchlorosilane and divinylbenzene [22]. One particular dynamic coating based on PEG 4000 was used for CIEF of microorganisms that were UV detected after focusing [26]. The same research group developed a fluorescence detection scheme based on the labeling of 4-[(1-pyrene)butanoate] (PB), which forms a fluorescent intermolecular excimer with amino groups on the surface of the microorganisms being analyzed, rendering them fluorescent after their electrophoretic separation [27]. In an exciting development, the same group later combined the PB detection scheme with CIEF [28]. Here, they synthesized PEG-PB and this molecule played dual role as both a dynamic coating and a fluorescent reagent, making it possible to detect down to ten cells. These researchers demonstrated this technique by analyzing 11 different species (see Fig. 1).

An issue, frequently encountered in the analysis of microorganisms is their low concentration in real samples. Improvements in detectability have been reported $[29,30]$. Yu and $\mathrm{Li}$ [29] used large-volume sample stacking with polarity switching to enrich the sample up to 60-fold. This approach was compatible with the CE separation of two E. coli strains. The Armstrong group [30,31] used a sweeping method based on the injection of a microbial sample, a buffer spacer plug, and a blocking agent plug. When the electric field is applied, the microorganisms in the sample plug migrate towards the cathode due to their coating with $\mathrm{CTAB}$; when they reach the blocking agent plug, they aggregate and lose their electrophoretic mobility; the aggregated plug then begins to migrate towards the anode. Using this concentration approach, the authors were able to detect single microorganisms in a commercial CE-LIF instrument [30].

The advantage of $\mathrm{CE}$ techniques for the identification and detection of microorganisms lies in their short separation times (e.g. 10-20 min) compared to conventional microbiological assays (e.g. 1 day). A review praising the speed advantage of CE over classical bacteriological methods for the analysis of Helicobacter pylori has recently appeared [32]. The CE community is currently working toward the development of even faster methodologies. Shintani et al. [33] have developed a microchip capillary electrophoretic assay for separating and detecting microorganisms in less than $3 \mathrm{~min}$. Liu et al. [34] have reported promising results using CIEF followed by whole-column imaging detection. 
Reports that demonstrate the clear advantages of capillary electrophoretic techniques for the analysis of microorganisms have begun to appear [23-25,35,36]. The analysis of $E$. coli and Helicobacter pylori, common in urinary tract infections and gastric diseases, respectively, was demonstrated in real samples [25]. For example, the CE analysis of urine infected with E. coli indicates the feasibility of this technique for real sample analysis. The use of CIEF to distinguish between the IEF profiles of native microorganisms and those that have been inactivated (i.e. by boiling, ethanol, formaldehyde, peroxoacetic acid) was demonstrated, suggesting that this method could be used to investigate microorganism infectivity [35]. A related report used CE-LIF to investigate the effects of antibiotics on Pseudomonas spp. and Streptococcus ssp. [24]. Live and dead microorganisms were selectively detected because of the respective accumulations of the permeable SYTO9 and impermeable propidium iodide.

It was reported that differences in viability could be observed by both fluorescence response and electrophoretic mobility patterns. Differences in the $\mathrm{p} I$ of biofilm-positive and biofilmnegative strains of Staphylococcus epidermidis were also demonstrated, indicating that it may be possible to use CIEF to determine the virulence of the various strains of this microorganism [36]. The same team also showed that both CIEF and CZE are highly suitable for the analysis of plant pathogens such as Pseudomonas sp. [37].

One of the challenges most often encountered when using CE to analyze microorganisms in real samples is that the complex backgrounds can make the identification of targeted microorganisms impossible. A nice demonstration of the successful selective detection of Staphylococcus aureus in the presence of other microorganisms was reported by Gao et al. [23]. They used mAb-coated latex particles to enrich for S. aureus and then fluorescent immunolabeling of the bound $S$. aureus for their selective detection by CE-LIF. The other microorganisms present were not detected here.

\section{Subcellular analysis}

Subcellular particles include membrane-bond intracellular organelles such as nuclei, mitochondria and lysosomes. It has been suggested that measuring the properties of individual organelles may enable us to study subcellular heterogeneity and to characterize organelle subpopulations. A general review covering the effort to develop techniques for the single-cell analysis of individual organelles has appeared [38]. The CE analysis of subcellular particles has included the analysis of new types of subcellular particles [7,39,40], separation conditions [41], improved detection arrangements [42,43], new applications [4446] and new sampling and labeling schemes [47-49].

\subsection{Capillary coatings}

The greatest problem connected with the $\mathrm{CE}$ of biological particles is most often the adsorption of particles on the inner surface of silica capillaries. Whiting et al. [41] have reported a separation of individual organelles (mitochondria from rat and mouse liver) in uncoated and dynamically coated capillaries. It was possible to separate mouse liver mitochondria on bare capillaries without significant amounts of carryover between 30-min runs. In the case of rat liver mitochondria, much stronger interactions with the capillary walls were observed and it was impossible to obtain reproducible data. Improvements in these separations and reductions in carryover were achieved when $0.2 \%$ polyvinyl alcohol was added to the separation buffer to serve as a dynamic coating. This work indicated that researchers should choose between bare capillaries, dynamically modified capillaries and covalently modified capillaries based on the nature and type of the subcellular particles to be investigated. 


\subsection{Instrumentation for the analysis of individual particles}

The Arriaga group [50] introduced the use of CE-LIF for the analysis of biological particles. In these studies, the particles were separated in the capillary according to their electrophoretic mobilities. At the capillary end, particles were hydrodynamically focused into the sheath flow cuvette, similar to analyses done in a flow cytometer. The passage of each particle in front of a laser beam produced a fluorescence signal corresponding to each particle.

The analytical performance of the home-built CE-LIF was compared with that of a commercial flow cytometer was compared using fluorescently labeled microspheres and isolated mitochondria [51].

CE-LIF was found to provide at least a 25 times higher S/N than flow cytometry for all types of particles. Moreover, only CE-LIF was able to reproducibly detect particles smaller than $0.2 \mu \mathrm{m}$. CE-LIF also detected both the high and low intensity events with reasonable RSD. On the other hand, flow cytometer showed lower RSD when analyzing larger particles. Both techniques demonstrated similar RSD when analyzing $10-N$-nonyl acridine orange (NAO)-labeled mitochondria, which was possibly caused by the more extensive photobleaching in the CE-LIF experiment. The advantage of flow cytometry was higher throughput (thousands of particles per second) and shorter analysis time. CE-LIF demonstrated a unique ability to measure the electrophoretic mobilities of individual particles with lower sample consumption.

Andreyev et al. [43] described a light scattering-LIF (LS-LIF) detector for submicrometer particle $\mathrm{CE}$ analysis. In this detector, when particles migrated through the sheath-flow cuvette, the fluorescence and scattered laser light were collected at a $90^{\circ}$ angle by an objective and focused on a glass beam splitter: (1) One beam was passed through a neutral density filter and a narrow bandpass filter onto a photomultiplier tube (PMT) to remove the fluorescence and to measure the intensity of scattered light (in this case $488 \mathrm{~nm}$ ); (2) The second beam was passed through a 505-nm long-pass filter to remove the scattered light and another bandpass filter to select the fluorescence wavelength onto the second PMT. The detection scheme was used to simultaneously monitoring both the fluorescence and scattering of electrophoretically separated, fluorescently labeled latex microspheres and mitochondria.

Ahmadzadeh et al. [42] reported a modification of a commercial CE instrument in order to combine two attractive features: automation and individual particle detection. The LIF oncolumn detector used in the instrument was additionally equipped with an external I/O board that allowed an increased data acquisition rate. Using $100 \mathrm{~Hz}$ instead of the manufacturer's setting of $4 \mathrm{~Hz}$ increased the total number of detected particles from 25 to $88 \%$ of the total number of particles predicted to be in the sample. Even though their LOD are higher than those of home-built CE-LIF instruments, the commercial instruments widely found in laboratories should be capable of the analysis of microparticles containing attomole levels of fluorophores.

\subsection{Applications of CE-LIF to individual organelle analysis}

Recent reports have included the use of CE-LIF for the analysis of acidic organelles [40], drug content [39,46], mitochondrial DNA content [45] and superoxide production [44].

It is hypothesized that acidic organelles, including endosomes and lysosomes, play an important role in the cellular metabolism of chemotherapeutic drugs in certain forms of multidrug resistance. Chen et al. [39] studied the properties of individual acidic organelles isolated from human leukemia CCRF-CEM and CEM/C2 cells using CE-LIF. The amount 
of anthracycline doxorubicin (DOX), a clinically important antitumor drug, which had accumulated in individual organelles, was quantified using CE with dual channel LIF detection. This was achieved by the simultaneous monitoring of fluorescence signals produced by endocytosed 50-nm fluorescein-labeled latex nanospheres (emission $\sim 520 \mathrm{~nm}$ ) and accumulated doxorubicin (emission $\sim 630 \mathrm{~nm}$ ) in acidic organelles. The average amount of DOX per acidic organelle was found to be $10.6 \mathrm{zmol}$ and $11.1 \mathrm{zmol}$ in CCRF-CEM and $\mathrm{CEM} / \mathrm{C} 2$ cells, respectively. In addition, the electrophoretic mobilities of acidic organelles and other organelles (mainly mitochondria) containing DOX were determined. The median electrophoretic mobility of the acidic organelles was found to be $-1.56 \times 10^{-4} \mathrm{~cm}^{2} \mathrm{~V}^{-1} \mathrm{~s}^{-1}$ and that of other DOX containing organelles $-2.1 \times 10^{-4} \mathrm{~cm}^{2} \mathrm{~V}^{-1} \mathrm{~s}^{-1}$. The latter value correlated well with the value obtained for mitochondria in other studies [41,52]. Chen et al. [7] were able to measure $\mathrm{pH}$ inside individual acidic organelles. The $\mathrm{pH}$ gradient between the acidic organelles and cytoplasm is considered one of the factors involved in some forms of multidrug resistance. In this study, the ratiometric dye fluorescein tetramethylrhodamine dextran (FRD) was used. The dye was bound to dextran to make its endocytosis into the cells and accumulation in acidic organelles possible. The FRD probe has two fluorophores: fluorescein with $\mathrm{pH}$-dependent fluorescence, and tetramethylrhodamine with $\mathrm{pH}-$ independent fluorescence. By measuring the signal ratio between their two emission wavelengths (530 and $590 \mathrm{~nm}$ ) and comparing it with a calibration curve, the $\mathrm{pH}$ value of a particular region could be obtained independent of FRD concentration. Here, median $\mathrm{pH}$ values of acidic organelles cells were found to be 5.0 and 6.1 for CEM/C2 and CCRF-CEM cells, respectively.

Mitochondria are producers of reactive oxygen species (ROS), including a superoxide $\left(\mathrm{O}_{2}^{-}\right)$ anion. Superoxide is involved in the oxidative damage of mitochondrial proteins, lipids and DNA, that is associated with the progression of aging. Meany et al. [44] developed a CELIF method for measuring the superoxide released within mitochondria in the human osteosarcoma 143B cell line (see Fig. 2). Superoxide was detected through its ability to oxidize hydroxyethidine (HE), a membrane permeable compound that is able to diffuse into the mitochondrial matrix. The products of superoxide oxidation are fluorescent (emission maxima $\sim 650 \mathrm{~nm}$ ), while unreacted HE is non-fluorescent. The mitochondria were simultaneously labeled with the selective dye MitoTracker Green, allowing these researchers to distinguish between true mitochondria and other organelles that may also produce superoxide (e.g. microsomes). The effects of oxidative phosphorylation inhibitors on the electrophoretic mobility of mitochondria were also studied (see Fig. 3). A similar technique for monitoring the effect of DOX on ROS production in individual mitochondria using a different fluorogenic dye, $2^{\prime}, 7^{\prime}$-dichlorodihydrofluorescein diacetate (DCFH-DA), has been published by Eder et al. [46].

Recently, Navratil et al [45]. published a direct CE-LIF method for the determination of mitochondria DNA (mtDNA) copy numbers in individual mitochondrial particles from 143B cells. Variations in mtDNA copy number in mitochondria, as well as the point mutations in the mtDNA chain, have been linked to aging, diabetes and several diseases. Mitochondria were fluorescently labeled by the transfection of 143B cells to express the DsRed2 fluorescent protein (emission maxima $\sim 582 \mathrm{~nm}$ ) that targets the mitochondrial matrix. Upon cell disruption, only the intact mitochondria retained DsRed2 and remained fluorescent. The mtDNA was also labeled quantitatively using PicoGreen; this labeling was necessary to exclude potentially contaminating organelles. After the CE separation, only those events with both DsRed2 and PicoGreen fluorescence were evaluated. The absolute quantitation of mtDNA was done by comparing the CE-LIF results with those produced by quantitative PCR. It was found that individual mitochondrial particles contained from 1 to 22 copies of mtDNA, with the majority of events containing only a single mtDNA copy. 


\subsection{Single cells and tissues}

Early publications in this area describe only the CE-LIF analysis of individual organelles in samples prepared in bulk from large amounts of cells. These methods do not allow researchers to track the origin of each individual organelle, information that is necessary for investigating a cell-to-cell variations [15,17].

Johnson et al. [47] have described the in-capillary isolation of mitochondria from a single 143B cell, followed by their electrophoretic separation and fluorescence detection. A single cell treated with NAO was hydrodynamically injected from a microscope slide into the capillary after a prior injection of a plug of digitonin/trypsin solution. The cell was then electrophoretically displaced to the digitonin/trypsin plug where its plasma membrane lysed, thereby releasing organelles. These organelles were separated using $-300 \mathrm{~V} / \mathrm{cm}$ and detected with a two-channel post-column LIF detector. Chen et al. [53] used the same approach to investigate a cell-to-cell variation in DOX distribution among the acidic organelles in CCRF-CEM cells. The cells were incubated with Alexa 488-labeled dextran and DOX. By detecting the accumulated Alexa 488 dextran, it was found that on average the CCRM-CEM cell contained 67 acidic organelles. The DOX content within the acidic organelles varied between $1.9 \times 10^{-22}$ and $9.4 \times 10^{-20}$ mole/organelle.

Ahmadzadeh et al. [48] have reported the hyphenation of a technique for solid tissue sampling with CE-LIF separation of individual mitochondria. Subsequently, they used oncolumn labeling of mitochondria released from tissue. In this case, a plug of NAO was first introduced into the capillary. Then, the tissue was sampled by bringing the capillary into close contact with a resin that had been pretreated with trypsin. A second NAO plug was then injected, and 5 min of incubation led to NAO labeling of the mitochondria. The released organelles were then subjected to CE-LIF. This hyphenation technique was also employed to study changes in individual mitochondrial particles associated with skeletal muscle fiber type and age [49], using two muscle fiber types (soleus and gastrocnemius) from rats at two different ages. Muscle type-specific and age-specific differences in the number of mitochondrial particles, their florescence intensities and electrophoretic mobilities were found.

\subsection{Microfluidic devices}

Duffy et al. [52] used the $\mu$-chip CE-LIF to study individual mitochondrial events isolated from bovine liver. This method offered five times shorter analysis times than similar separations performed in capillaries with equal sensitivity. Whiting et al. [54] increased detection sensitivity when detecting mitochondria in the glass microchip devices by using an orthogonal detection arrangement, but warn the reader about limitations in the dynamic range of the number of particles in one sample. Similar limitations have also been mentioned in a related CE study [55].

\section{Viral particles}

The genetic material of virus particles (DNA or RNA) is to be found within a protective envelope made of capsid. Since the first paper about the application of CZE to the analysis of viruses appeared [56], there has been continued interest in the analysis of various viruses using electrophoretic techniques [57]. Recently, Kenndler's group continued their investigation of the composition of human rhinoviruses (HRV), the main agents of the common cold, using CE techniques. HRV are composed of a RNA genome surrounded by an icosahedral shell comprising 60 copies of four viral proteins VP1-VP4. During the viral infection pathway, the original viral particle loses its innermost capsid protein VP4 and forms an $\mathrm{A}-$ or $135 \mathrm{~S}$ (sedimentation coefficient in the sucrose density gradient) particle. 
When the viral RNA is released into the cytosol (e.g. by high temperature or $\mathrm{pH}$ change), the resulting particles, known as particles B- or 80S, consist of three capsid proteins, VP1-3.

Kremser et al. studied the effects of detergent additives on the stability and electrophoretic mobility of subviral particles. They found the commonly used surfactant, SDS, to be incompatible with the analysis of subviral particles because the particles disintegrated into their protein components VP1, VP2 and VP3 in the presence of SDS. They discovered that dodecyl-PEG ether) (D-PEG, commercially known as Thesit or Brij) is more conducive to stable viral particles (see Fig. 4) [58]. D-PEG generally contains a hydrophobic C12 chain, which is connected to another chain consisting of polyethoxy units. The $\mathrm{C} 12$ chains form a micelle liphophilic core surrounded by the hydrophilic polyethylene chains. When used as a buffer additive in $10 \mathrm{mM}$ concentration, the $80 \mathrm{~S}$ particles were successfully identified in the electropherogram as a broad peak. In comparison, when the SDS had been used, there was no single peak and four peaks belonging to the viral proteins VP1-4 had occurred.

This new system was then used to study of the interactions between the $80 \mathrm{~S}$ viral particles from HRV2 virus with the $\mathrm{mAb} 2 \mathrm{G} 2$ [59]. This antibody can only recognize the epitope presented on the $80 \mathrm{~S}$ - and $135 \mathrm{~S}$ - particles, and not that on the native virus. The existence of a virus-antibody complex was documented by comparing electropherograms of native HRV2, 80S- particles and a product of the reaction of viral particles with mAb $2 \mathrm{G} 2$.

Liu and Pawliszyn [60] used the CIEF with whole-column imaging detection (WCID) scheme for the investigation of viral particles and their interactions with antibodies. In CIEF-WCID, analytes are first focused into separated bands and subsequently the whole capillary is imaged with a CCD camera. This approach eliminates the mobilization step that is necessary in standard CIEF. CIEF-WCID was used in two different arrangements; to image UV absorption (CIEF-UV-WCID) and to detect the fluorescently labeled analytes axially illuminated by a laser (CIEF-LIF-WCID). Both arrangements helped in the study of the interactions of a MS2 bacteriophage with anti-MS2 antibodies [61]. Noncovalent labeling of the MS2-antibody complexes by the NanoOrange fluorescent dye was also documented in this paper.

\section{Concluding remarks}

The $\mathrm{CE}$ is becoming an important technique for the analysis of biological particles, including microorganisms, viruses, intact cells and organelles. Both CZE and IEF have been equally used. Highlights are (i) the use of CZE to separate individual organelles and characterize subcellular heterogeneity, (ii) the use of IEF to distinguish between microbiological species or to determine microorganism status, and (iii) the characterization of viral assemblies. Using liposomes as bioparticle models, theories describing the electrophoretic behavior of bioparticles continue being refined. Practical approaches for addressing bioparticle stability issues as well as adsorption to the capillary walls were reported, and these successful approaches are giving rise to many exciting developments in the analysis of microorganisms. The LIF detection continues being the best approach for attaining the best LOD, although WCID is emerging as a powerful alternative. A few examples of bioparticle separations performed on microfluidic devices suggest that these tools are promising to overcome the lower throughput of conventional CE techniques. The papers covered by this review suggest that $\mathrm{CE}$ has found a new niche in the fields of microbiology, virology, subcellular analysis, and bionanotechnology.

\section{Acknowledgments}

This work was supported by the National Institutes of Health (R01-AG20866) and E. A. A. is supported by a NIH Career Award (1K02-AG21453). 


\section{References}

1. Righetti PG. J Chromatogr A 2005;1079:24-40. [PubMed: 16038288]

2. Fredlake CP, Hert DG, Mardis ER, Barron AE. Electrophoresis 2006;27:3689-3702. [PubMed: 17031784]

3. Bakry R, Huck CW, Najam-ul-Haq M, Rainer M, Bonn GK. J Sep Sci 2007;30:192-201. [PubMed: 17390613]

4. Padarauskas A. Anal Bioanal Chem 2006;384:132-144. [PubMed: 16331445]

5. Kašička V. Electrophoresis 2006;27:142-175. [PubMed: 16307429]

6. Rodriguez MA, Armstrong DW. J Chromatogr B 2004;800:7-25.

7. Chen Y, Arriaga EA. Langmuir 2007;23:5584-5590. [PubMed: 17402758]

8. Pysher MD, Hayes MA. Langmuir 2004;20:4369-4375. [PubMed: 15969140]

9. Pysher MD, Hayes MA. Langmuir 2005;21:3572-3577. [PubMed: 15807603]

10. Owen RL, Strasters JK, Breyer ED. Electrophoresis 2005;26:735-751. [PubMed: 15714573]

11. Bilek G, Kremser L, Blaas D, Kenndler E. J Chromatogr B 2006;841:38-51.

12. Hayes MA, Pysher MD, Chen K. J Nanosci Nanotechnol 2007;7:2283-2286. [PubMed: 17663241]

13. Bilek G, Kremser L, Wruss J, Blaas D, Kenndler E. Anal Chem 2007;79:1620-1625. [PubMed: 17297964]

14. Bilek G, Kremser L, Blaas D, Kenndler E. Electrophoresis 2006;27:3999-4007. [PubMed: 16983637]

15. Woods LA, Roddy TP, Ewing AG. Electrophoresis 2004;25:1181-1187. [PubMed: 15174037]

16. Arcibal IG, Santillo MF, Ewing AG. Anal Bioanal Chem 2007;387:51-57. [PubMed: 16912862]

17. Sims CE, Allbritton NL. Lab Chip 2007;7:423-440. [PubMed: 17389958]

18. Xiao H, Li X, Zou HF, Yang L, et al. Anal Chim Acta 2006;556:340-346.

19. Omasu F, Nakano Y, Ichiki T. Electrophoresis 2005;26:1163-1167. [PubMed: 15704247]

20. Akagi T, Suzuki M, Ichiki T. Jpn J Appl Phys 2006;45:L1106-L1109.

21. Gao N, Wang WL, Zhang XL, Jin WR, et al. Anal Chem 2006;78:3213-3220. [PubMed: 16643017]

22. Szumski M, Klodzinska E, Buszewski B. J Chromatogr A 2005;1084:186-193. [PubMed: 16114253]

23. Gao P, Xu G, Shi X, Yuan K, Tian J. Electrophoresis 2006;27:1784-1789. [PubMed: 16645942]

24. Hoerr V, Ziebuhr W, Kozitskaya S, Katzowitsch E, Holzgrabe U. Anal Chem 2007;79:7510-7518. [PubMed: 17784732]

25. Klodziniska E, Dahm H, Rozycki H, Szeliga J, et al. J Sep Sci 2006;29:1180-1187. [PubMed: 16830734]

26. Horka M, Ruzicka F, Horky J, Hola V, Slais K. J Chromatogr B 2006;841:152-159.

27. Horka M, Ruzicka F, Hola V, Šlais K. Electrophoresis 2005;26:548-555. [PubMed: 15690456]

28. Horka M, Ruzicka F, Horky J, Hola V, Šlais K. Anal Chem 2006;78:8438-8444. [PubMed: 17165837]

29. Yu L, Li SF. J Chromatogr A 2007;1161:308-313. [PubMed: 17559861]

30. Lantz AW, Bao Y, Armstrong DW. Anal Chem 2007;79:1720-1724. [PubMed: 17297979]

31. Rodriguez MA, Lantz AW, Armstrong DW. Anal Chem 2006;78:4759-4767. [PubMed: 16841893]

32. Buszewski B, Klodzinska E, Dahm H, Rozycki H, et al. Biomed Chromatogr 2007;21:116-122. [PubMed: 17221910]

33. Shintani T, Torimura M, Sato H, Tao H, Manabe T. Anal Sci 2005;21:57-60. [PubMed: 15675517]

34. Liu Z, Wu SS, Pawliszyn J. J Chromatogr A 2007;1140:213-218. [PubMed: 17166508]

35. Horka M, Kubicek O, Ruzicka F, Hola V, et al. J Chromatogr A 2007;1155:164-171. [PubMed: 17328903]

36. Ruzicka F, Horka M, Hola V, Votava M. J Microbiol Methods 2007;68:530-535. [PubMed: 17157942] 
37. Horka M, Horky J, Matouskova H, Šlais K. Anal Chem 2007;79:9539-9546. [PubMed: 17997525]

38. Olson KJ, Ahmadzadeh H, Arriaga EA. Anal Bioanal Chem 2005;382:906-917. [PubMed: 15928950]

39. Chen Y, Walsh RJ, Arriaga EA. Anal Chem 2005;77:2281-2287. [PubMed: 15828758]

40. Chen Y, Arriaga EA. Anal Chem 2006;78:820-826. [PubMed: 16448056]

41. Whiting CE, Arriaga EA. Electrophoresis 2006;27:4523-4531. [PubMed: 17117462]

42. Ahmadzadeh H, Dua R, Presley AD, Arriaga EA. J Chromatogr A 2005;1064:107-114. [PubMed: 15729825]

43. Andreyev D, Arriaga EA. Anal Chem 2007;79:5474-5478. [PubMed: 17555300]

44. Meany DL, Poe BG, Navratil M, Moraes CT, Arriaga EA. Free Radic Biol Med 2006;41:950-959. [PubMed: 16934678]

45. Navratil M, Poe BG, Arriaga EA. Anal Chem 2007;79:7691-7699. [PubMed: 17877423]

46. Eder AR, Arriaga EA. Chem Res Toxicol 2006;19:1151-1159. [PubMed: 16978019]

47. Johnson RD, Navratil M, Poe BG, Xiong GH, et al. Anal Bioanal Chem 2007;387:107-118. [PubMed: 16937092]

48. Ahmadzadeh H, Thompson LV, Arriaga EA. Anal Bioanal Chem 2006;384:169-174. [PubMed: 16320040]

49. Ahmadzadeh H, Andreyev D, Arriaga EA, Thompson LV. J Gerontol Ser A - Biol Sci Med Sci 2006;61:1211-1218. [PubMed: 17234813]

50. Duffy CF, Gafoor S, Richards DP, Admadzadeh H, et al. Anal Chem 2001;73:1855-1861. [PubMed: 11338602]

51. Poe BG, Navratil M, Arriaga EA. J Chromatogr A 2006;1137:249-255. [PubMed: 17070532]

52. Duffy CF, MacCraith B, Diamond D, O'Kennedy R, Arriaga EA. Lab Chip 2006;6:1007-1011. [PubMed: 16874370]

53. Chen Y, Xiong G, Arriaga EA. Electrophoresis 2007;28:2406-2415. [PubMed: 17577888]

54. Whiting CE, Dua RA, Arriaga EA. Electrophoresis. 2007 in press.

55. Whiting CE, Arriaga EA. J Chromatogr A 2007;1157:446-453. [PubMed: 17521658]

56. Hjerten S, Elenbring K, Kilar F, Liao JL, et al. J Chromatogr 1987;403:47-61. [PubMed: 2445770]

57. Kremser L, Bilek G, Blaas D, Kenndler E. J Sep Sci 2007;30:1704-1713. [PubMed: 17623450]

58. Kremser L, Petsch M, Blaas D, Kenndler E. Electrophoresis 2006;27:1112-1121. [PubMed: 16523456]

59. Kremser L, Petsch M, Blaas D, Kenndler E. Electrophoresis 2006;27:2630-2637. [PubMed: 16732623]

60. Liu Z, Pawliszyn J. Anal Biochem 2005;336:94-101. [PubMed: 15582563]

61. Liu Z, Pawliszyn J. Electrophoresis 2005;26:556-562. [PubMed: 15690457]

\section{Abbreviations}

$\begin{array}{ll}\text { DOX } & \text { doxorubicin } \\ \text { FRD } & \text { fluoresceintetramethylrhodamine dextran } \\ \text { HRV } & \text { human rhinovirus } \\ \text { NAO } & 10-N \text {-nonyl acridine orange } \\ \text { PB } & 4-[(1-\text { pyrene }) \text { butanoate }] \\ \text { PGP } & \text { P-glycoprotein } \\ \text { PO } & \text { peroxidase } \\ \text { WCID } & \text { whole column imaging detection }\end{array}$



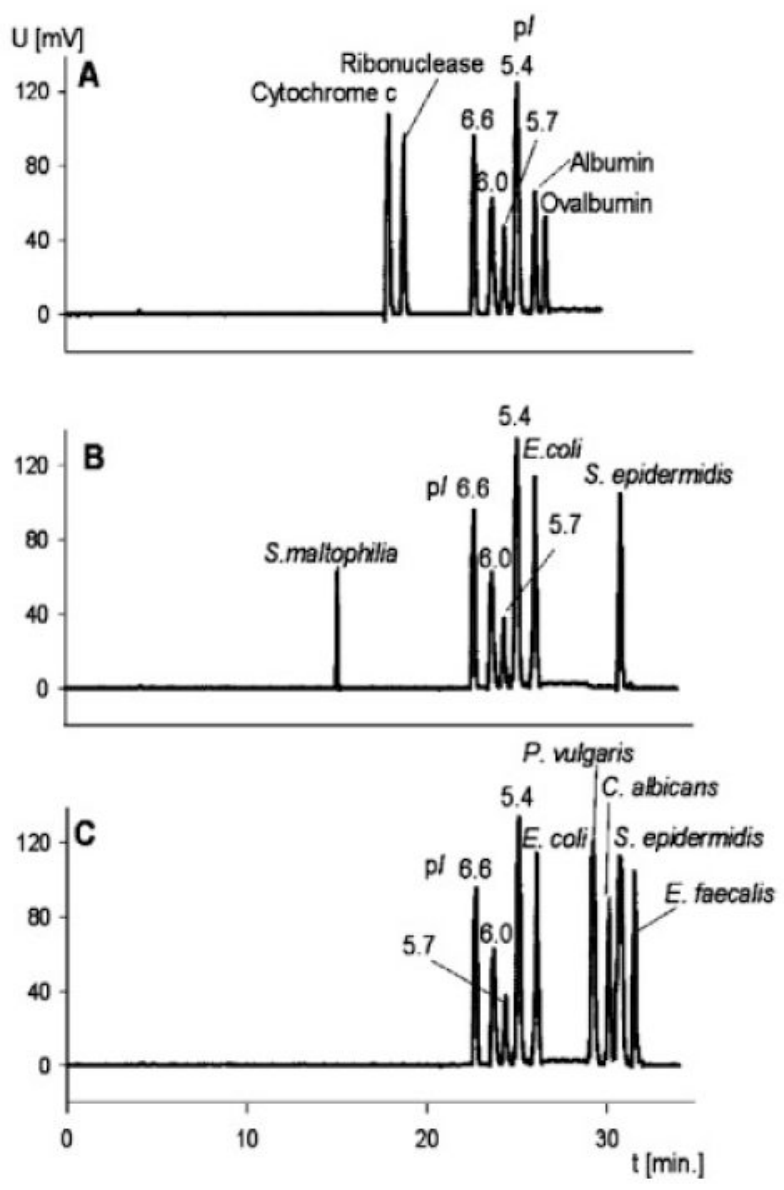

Figure 1.

CIEF of $\mathrm{p} I$ markers, proteins and frequent pathogens of the urinary tract infections, $\mathrm{pH}$ gradient 2-11. Conditions and designations: FS $0.1 \mathrm{~mm}$ id, $0.25 \mathrm{~mm}$ od, length $320 \mathrm{~mm}, 250$ $\mathrm{mm}$ to the detection cell; applied voltage (-) $20 \mathrm{kV}$; buffer, $2 \times 10^{-2} \mathrm{~mol} / \mathrm{L}$ phosphate buffer. (A) Sample segment $-c_{\mathrm{PB}-\mathrm{PEG}, \text { inj }}, 7 \times 10^{-4} \mathrm{~mol} / \mathrm{L}$; $c_{\mathrm{PB}-\mathrm{PEG}, \mathrm{CaAn}}, 1 \times 10^{-4} \mathrm{~mol} / \mathrm{L}$; proteins mixture, cytochrome c, ribonuclease $\mathrm{A}$, albumin, and ovalbumin; $\Delta h$ of proteins, $160 \mathrm{~mm}$, $t_{\text {inj }}, 14 \mathrm{~s} ; \lambda_{\text {EM }}, 480 \mathrm{~nm}$. (B) See (A) sample segment $-c_{\text {PB-PEG,inj }}, 2 \times 10^{-4} \mathrm{~mol} / \mathrm{L}, \mathrm{c}_{\mathrm{EtOH}, \mathrm{inj}}$, $20 \% \mathrm{v} / \mathrm{v} ; \mathrm{C}_{\mathrm{PB}-\mathrm{PEG}, \mathrm{CaAn}}, 7 \times 10^{-5} \mathrm{~mol} / \mathrm{L}$; microorganism mixture, S. maltophilia, E. coli, $S$. epidermidis, $8 \times 10^{4} \mathrm{cell} / \mathrm{mL} ; \lambda_{\mathrm{EM}}, 480 \mathrm{~nm}$. (C) See (B) sample mixture of microorganisms, E. coli, $P$. vulgaris, S. epidermidis, C. albicans, and E. faecalis. Reprinted with permission from [28]. Copyright (2006) American Chemical Society. 

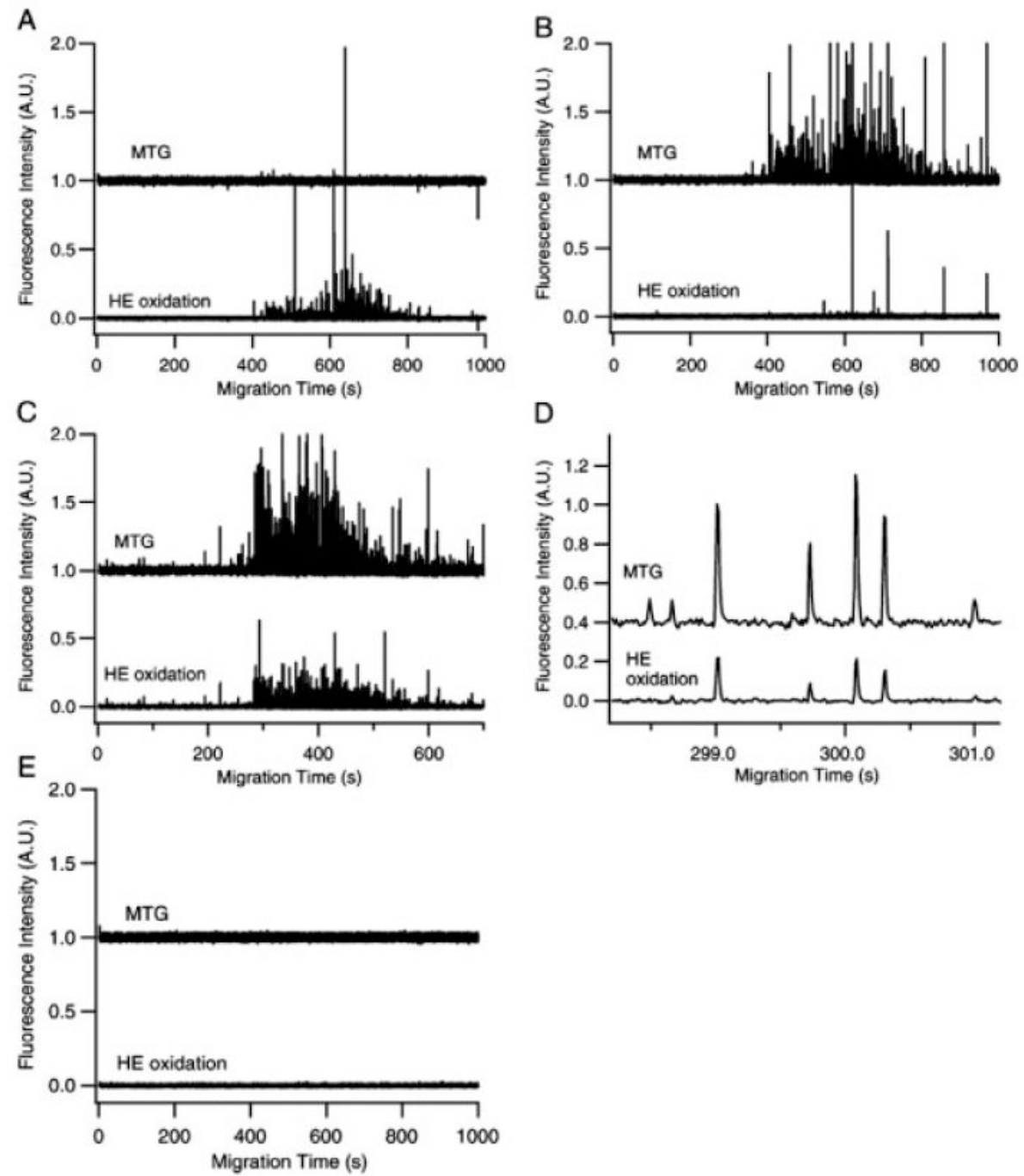

Figure 2.

Electropherograms of organelles isolated from 143B cells detected due to either MTG accumulation or HE oxidation. Samples were prepared from 143B cells treated with hydroxyethidine (HE) (A), MTG (B), and both HE and MTG (C). An expanded region of (C), showing mitochondria with and without detectable superoxide generation, is represented in (D). MTG detection was at $510 \pm 20 \mathrm{~nm}$ (top traces, $y$-offset for clarity). HE detection was at $635 \pm 27.5 \mathrm{~nm}$ (bottom traces). Separation was performed at $-300 \mathrm{~V} / \mathrm{cm}$ in CE running buffer; injection of enriched mitochondria samples was done hydrodynamically for $4 \mathrm{~s}$ at $5.5 \mathrm{kPa}$. A control prepared from 143B cells without any treatment is shown in (E). Reprinted with permission from [44]. Copyright (2006) Elsevier. 


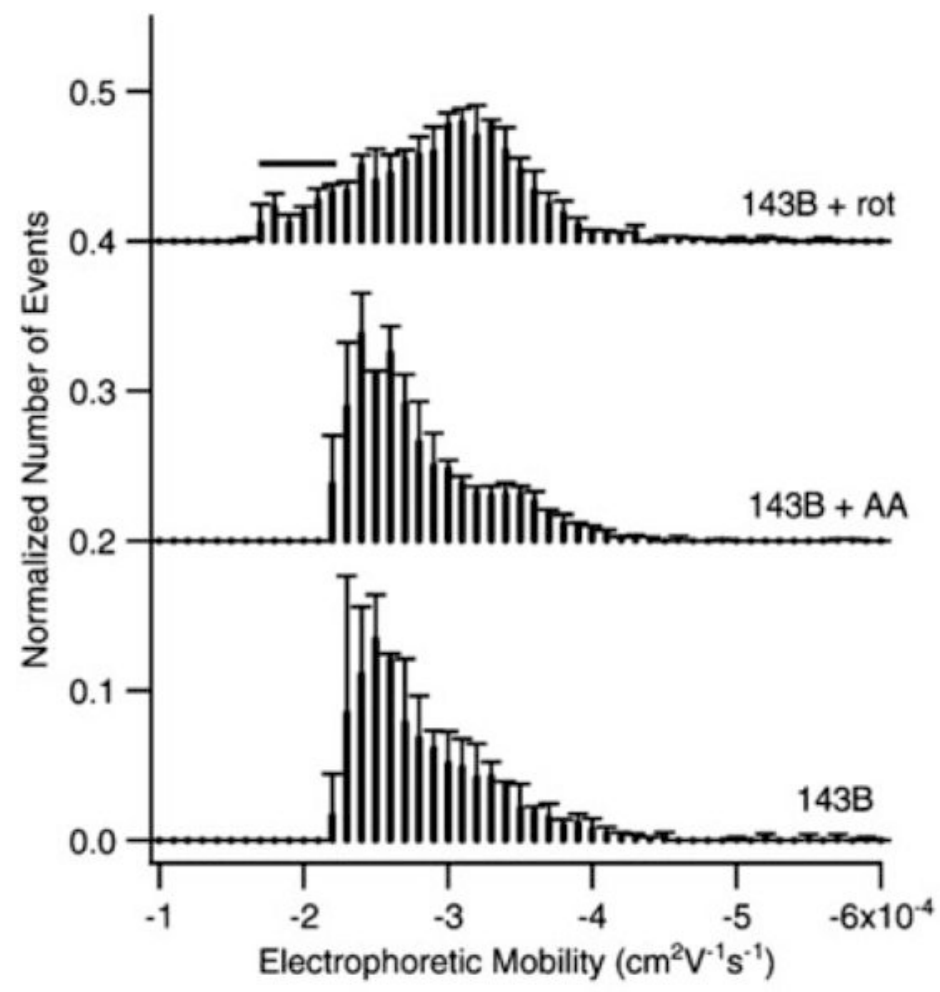

Figure 3.

Effect of antimycin A and rotenone on the electrophoretic mobility distributions of mitochondria with detectable superoxide levels. 143B, mitochondria from 143B cells without inhibitor treatment; 143B + AA, mitochondria from 143B cells treated with antimycin A (3 $\mu \mathrm{M}) ; 143 \mathrm{~B}+$ rot, mitochondria from 143B cells treated with rotenone (1 $\mu \mathrm{M})$. Reprinted with permission from [44]. Copyright (2006) Elsevier. 
(A)

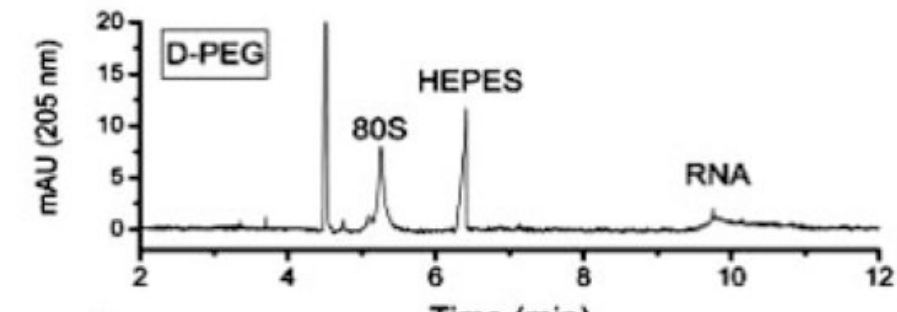

(B)

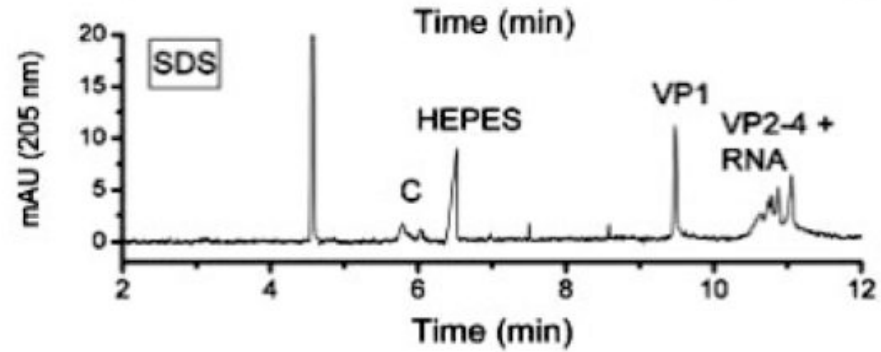

Figure 4.

Electropherograms of $80 \mathrm{~S}$ subviral B particles obtained in different BGE. The $80 \mathrm{~S}$ particles were produced from HRV2 $(0.03 \mu \mathrm{M})$, heated for $10 \mathrm{~min}$ to $56^{\circ} \mathrm{C}$ in $50 \mathrm{mM}$ borate, $\mathrm{pH} 8.3$. (A) BGE: $100 \mathrm{mM}$ borate $+10 \mathrm{mM}$ D-PEG, $\mathrm{pH}$ 8.3. (B) BGE: $100 \mathrm{mM}$ borate $+10 \mathrm{mM}$ SDS, $\mathrm{pH}$ 8.3. "C" denotes an uncharacterized contaminant always present in the virus preparations. Experimental conditions: bare fused-silica capillary, total length $68.0 \mathrm{~cm}$; length to detector $59.5 \mathrm{~cm}$; ID $50 \mu \mathrm{m}$. Voltage $+25 \mathrm{kV}$; sample injection 450 mbar. Detection wavelength: $205 \mathrm{~nm}$. HEPES is from the initial virus preparation. Reprinted with permission from [59]. Copyright (2006) Wiley-VCH Verlag GmbH \& Co. KGaA. 


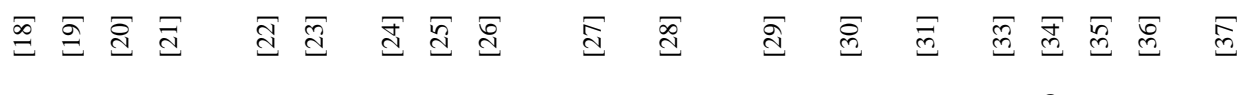

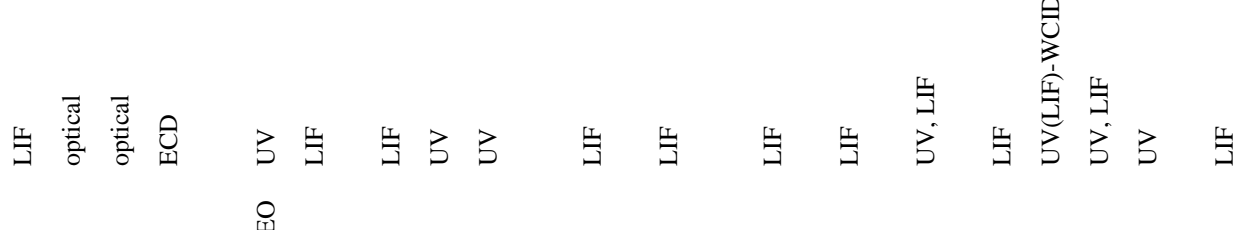

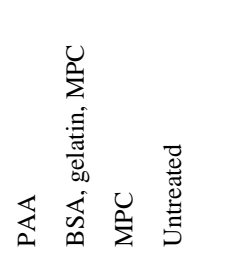

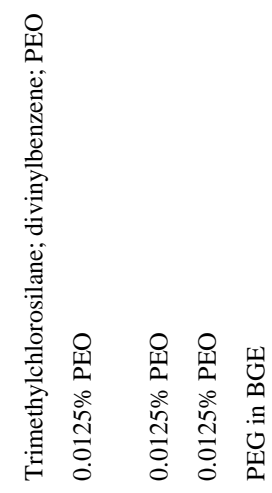

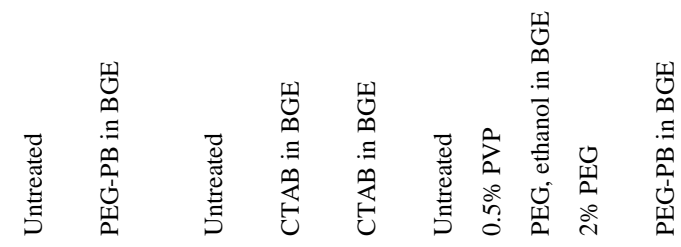

$\stackrel{\stackrel{+}{*}}{\stackrel{2}{2}}$

造

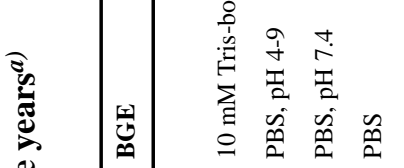

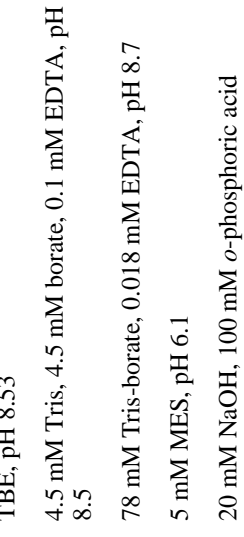

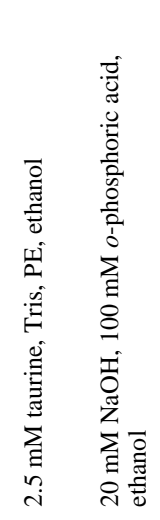

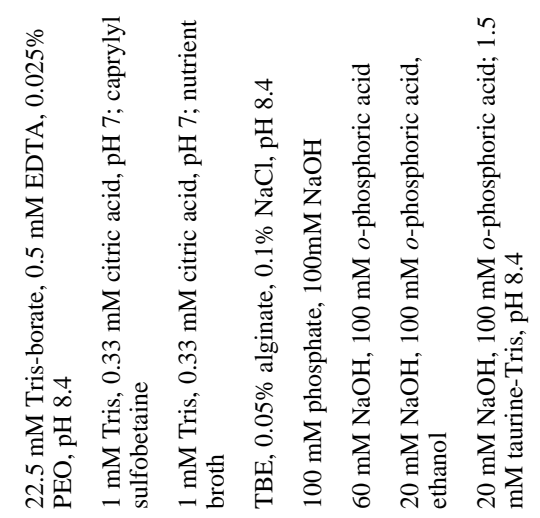

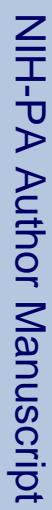

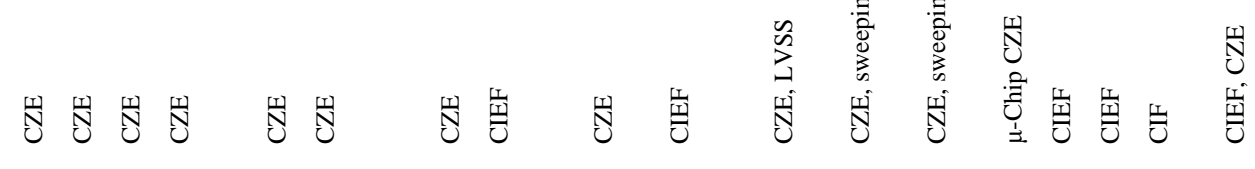

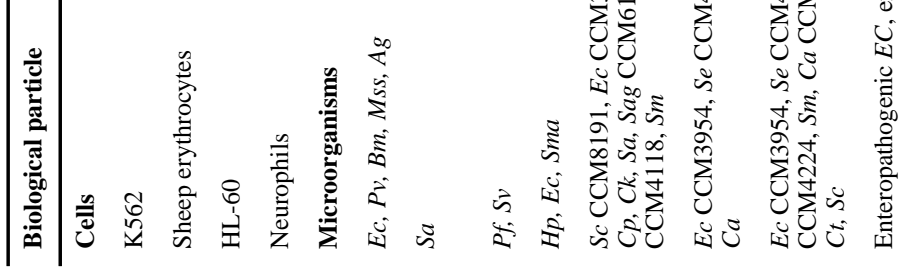

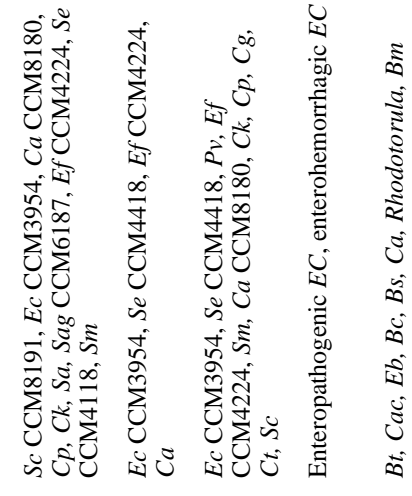

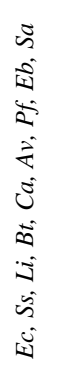

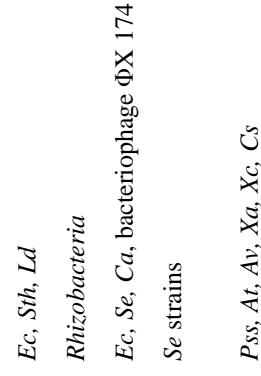

Electrophoresis. Author manuscript; available in PMC 2011 February 10. 


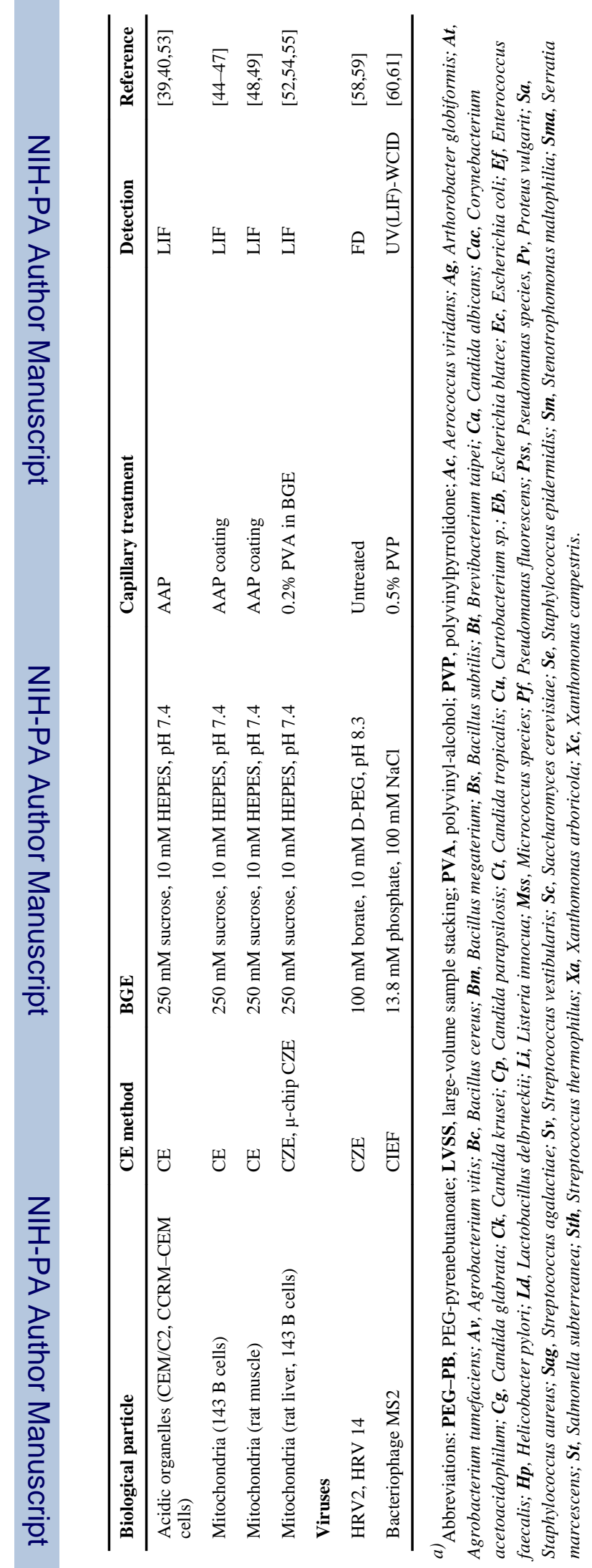

Electrophoresis. Author manuscript; available in PMC 2011 February 10. 